\title{
Laryngeal Myxoma: A Case Report and Review of the Literature
}

\author{
Angela Ritchie $\cdot$ Jay Youngerman $\cdot$ John E. Fantasia $\cdot$ \\ Leonard B. Kahn $\cdot$ Rubina S. Cocker
}

Received: 24 July 2013/Accepted: 13 August 2013/Published online: 22 August 2013

(C) Springer Science+Business Media New York 2013

\begin{abstract}
Myxomas are a rare benign neoplasm of uncertain mesenchymal cell origin, typically involving the heart. Laryngeal myxomas are uncommon, and are usually misdiagnosed as laryngeal polyp. To the best of our knowledge, there are only nine reported cases in the English literature. We report a case of a laryngeal myxoma presenting clinically as a left vocal cord polyp in a 77 year old male, and review the literature related to this rare entity.
\end{abstract}

Keywords Myxoma $\cdot$ Larynx $\cdot$ Vocal cord .

Laryngeal myxoma $\cdot$ Polyp

\section{Introduction}

Myxomas are benign tumors of mesenchymal origin that arise in bone as well as somatic soft tissues. The term myxoma was first described by Virchow in 1871 when he

\footnotetext{
A. Ritchie $(\bowtie)$ J. E. Fantasia

Division of Oral and Maxillofacial Pathology,

Department of Dental Medicine, Hofstra North Shore-LIJ

School of Medicine, 270-05 76th Avenue, New Hyde Park,

NY 11040, USA

e-mail: aritchie@nshs.edu

J. Youngerman

Department of Otolaryngology, Planview Hospital, 888 Old

Country Rd, Plainview, NY 11803, USA

L. B. Kahn · R. S. Cocker

Department of Pathology, Hofstra North Shore-LIJ School of Medicine, 900 Fulton Avenue, Hempstead, NY 11550, USA

R. S. Cocker

6 Ohio Drive Room 25, New Hyde Park, NY 11042, USA

e-mail: rcocker@nshs.edu
}

described tumors with a histologic similarity to the mucinous tissue of the umbilical cord [1]. Diagnostic criteria for myxomas were established in 1948 by Stout [2], who described myxomas as a true mesenchymal neoplasm consisting exclusively of undifferentiated stellate cells in a loose myxoid stroma that did not metastasize. In the head and neck, they occur most commonly in the mandible and maxilla and are likely odontogenic in origin. Bony myxomas are almost exclusive to the facial skeleton. Soft tissue myxomas occur most frequently in the skeletal muscle, subcutaneous tissue, fascial planes and neurovascular sheaths of the extremities. They may also be present in the face. Myxomas of the head and neck arise innocuously as a painless, slow growing mass [3]. Myxomas of the larynx are extremely rare with only nine reported cases in the English literature (Table 1). We document a case of a laryngeal myxoma and a review of the literature.

\section{Case Report}

A 77 year old male presented with a 6 month history of intermittent hoarseness with occasional complete dysphonia. He provided a history of heavy smoking but was currently smoking only two cigarettes per day. Medical history was significant for high cholesterol, hypertension, diabetes and hearing loss. Current medications included metformin, amlodipine, tamsulosin, cilostazol, citalopram, folic acid, hydrochlorothiazide, aspirin and Lipitor. On examination the patient presented with a raspy voice. The head and neck as well as intraoral examination appeared normal. The cranial nerves were all intact and the patient was well oriented. He had a deviated septum as well as inflamed turbinates. Flexible laryngoscopy revealed a large hypervascular lesion on the left cord. With motion the left 
Table 1 Ten cases of laryngeal myxoma

\begin{tabular}{|c|c|c|c|c|c|c|c|}
\hline $\begin{array}{l}\text { Age/ } \\
\text { sex }\end{array}$ & Complaint & Site & Size $(\mathrm{cm})$ & $\begin{array}{l}\text { Surgical } \\
\text { approach }\end{array}$ & $\begin{array}{l}\text { Alcohol/ } \\
\text { smoking Hx }\end{array}$ & Recurrence & Ref. \\
\hline $37 / \mathrm{M}$ & Dysphonia/Dysphagia & Epiglottis & $5.6 \times 4.3 \times 2.4$ & $\begin{array}{l}\text { Direct } \\
\text { laryngoscopy }\end{array}$ & ND & None & [1] \\
\hline 70/M & Hoarseness & Aryepiglotic fold & $0.5 \times 5.0 \times 2.5$ & $\begin{array}{c}\text { Transverse } \\
\text { excision }\end{array}$ & $\begin{array}{l}\text { Alcohol+ } \\
\text { Smoking }+\end{array}$ & None & {$[3]$} \\
\hline 64/M & Dysphonia & Vocal fold & $1.0 \times 0.6 \times 0.2$ & $\begin{array}{l}\text { Direct } \\
\text { laryngoscopy }\end{array}$ & $\begin{array}{l}\text { Alcohol+ } \\
\text { Smoking }+\end{array}$ & None & {$[11]$} \\
\hline $57 / \mathrm{M}$ & Hoarseness & Vocal fold & $0.7 \times 0.7 \times 0.7$ & $\begin{array}{l}\text { Direct } \\
\text { laryngoscopy }\end{array}$ & $\begin{array}{l}\text { Alcohol+ } \\
\text { Smoking ND }\end{array}$ & None & {$[5]$} \\
\hline $62 / \mathrm{M}$ & Dypsnea & Vocal fold & $2.5 \times 2.5 \times 1.5$ & $\begin{array}{l}\text { Direct } \\
\text { laryngoscopy }\end{array}$ & $\begin{array}{l}\text { Alcohol+ } \\
\text { Smoking+ }\end{array}$ & ND & {$[14]$} \\
\hline $42 / \mathrm{M}$ & Dypsnea & Vocal cord & ND & ND & ND & ND & {$[13]$} \\
\hline $57 / \mathrm{M}$ & $\begin{array}{l}\text { Difficulty swallowing/voice } \\
\text { change }\end{array}$ & $\begin{array}{l}\text { Aryepiglotic fold, } \\
\text { epiglottis }\end{array}$ & $6.5 \times 5.0 \times 1.0$ & $\begin{array}{l}\text { Direct } \\
\text { laryngoscopy }\end{array}$ & ND & None & {$[4]$} \\
\hline 46/M & Hoarseness & Vocal cord & 0.8 & $\begin{array}{l}\text { Direct } \\
\text { laryngoscopy }\end{array}$ & $\begin{array}{l}\text { Alcohol+ } \\
\text { Smoking ND }\end{array}$ & ND & [9] \\
\hline 74/M & Hoarseness & Vocal cord & 0.4 & $\begin{array}{l}\text { Direct } \\
\text { laryngoscopy }\end{array}$ & $\begin{array}{l}\text { Alcohol+ } \\
\text { Smoking ND }\end{array}$ & None & {$[8]$} \\
\hline 77/M & Hoarseness/Dysphonia & Vocal cord & $0.8 \times 0.3 \times 0.2$ & $\begin{array}{l}\text { Direct } \\
\text { laryngoscopy }\end{array}$ & $\begin{array}{l}\text { Alcohol- } \\
\text { Smoking+ }\end{array}$ & None & $\begin{array}{c}\text { Curren } \\
\text { case }\end{array}$ \\
\hline
\end{tabular}

$\mathrm{ND}=$ not determined, $+=$ positive history of use, $-=$ no history of use

cord lesion covered the right cord and appeared to compromise the airway. The videostrobe was consistent with severe Reinke's edema with narrowing of the airway (Fig. 1). The patient was taken to the operating room where under general anesthesia using a combination of a laryngeal mask airway and Venturi with a 14 gauge needle he underwent a direct suspension microlaryngoscopy. This procedure revealed minimal changes to the right cord with a large polypoid mass on the left cord. The mass was biopsied and upon opening the mucosa a submucosal mass bulged from the cord. Excisional biopsy was performed. The specimen consisted of a tan-pink rubbery polyp measuring $<1 \mathrm{~cm}$ as well as an aggregate of mucoid material of similar size. Histologic examination revealed a polypoid tissue fragment consisting of numerous stellate and spindled cells in a background of abundant mucoid material. The cells had small hyperchromatic nuclei with scant cytoplasm. There was no cellular pleomorphism and no mitotic figures were seen. Small, dilated blood vessels as well as cyst-like spaces were also scattered throughout the lesion. Fragments of laryngeal mucosa exhibiting hyperparakeratosis were also observed (Fig. 2). No fibroproteinaceous stroma was identified. The microscopic findings were consistent with a laryngeal myxoma. Immunohistochemical studies showed that the lesional cells stained positively for $\mathrm{CD} 34$ but were negative for $\mathrm{S} 100$ and smooth muscle actin. At 3 month follow up the patient is still hoarse and redundant mucosa was still present, but no signs of recurrence are observed.

\section{Discussion}

\section{Clinical Presentation}

Clinically, laryngeal myxomas generally present as a large polypoid mass. The most common location for a laryngeal myxoma is the vocal cord, followed by the vocal fold, aryepiglotic fold with one report describing involvement of the epiglottis. Laryngeal myxomas most commonly present with hoarseness, followed by dyspnea, dysphonia, dysphagia, and in rare cases a reported change in voice [4]. Hoarseness can occur when the myxoma is present on the vocal cord itself or when it arises from the aryepliglottic fold. Myxomas of the vocal cord cause direct disturbance of the vocal cord vibrations. Patients with myxomas of the aryepiglottic fold typically remain asymptomatic for longer periods of time as these lesions must reach considerable size before they disturb vocal cord function. If the myxoma arises from the lingual surface of the epiglottis, dysphonia and/or dysphagia will likely occur [5]. The size of the laryngeal myxomas range from approximately $0.5-7.0 \mathrm{~cm}$. 

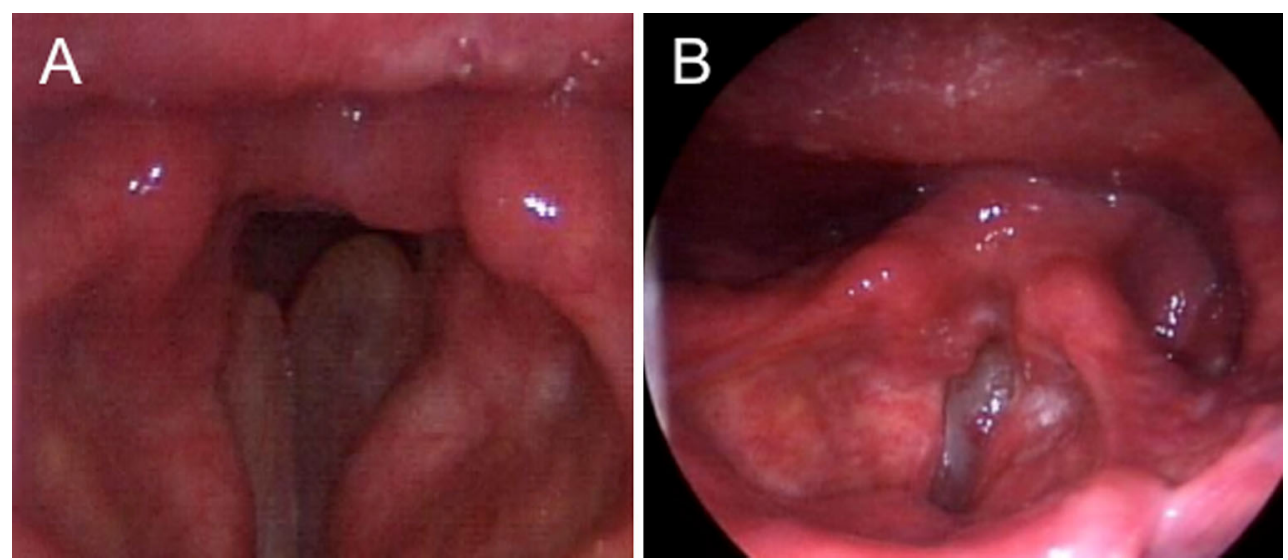

Fig. 1 Stoboscope images showing, a bilateral fullness in the vocal cords consistent with Reinke's edema. b In the mid-cord there is an erythematous fullness. Stroboscopically there was decreased mucosal wave and vibration of both vocal folds

Myxomas most commonly present as slow growing, wellcircumscribed masses, sometimes of several years duration. They may be present for several years and never change in size. Although myxomas are well-circumscribed, they lack a fibrous capsule and tend to grow via local infiltration [6].

\section{Etiology and Demographics}

The etiology of myxoma remains unclear. It is presumed they are derived from primitive embryonic mesenchyme or fibroblasts possessing the capacity to elaborate abundant mucopolysaccharides. Since the favored site is the jaw, consideration has been given to the origination from odontogenic primordial mesenchyme [7]. There is controversy as to whether myxomas are neoplastic or reactive. Stout provided support for myxomas being neoplastic and established diagnostic criteria [2].

Laryngeal myxomas display a strong male predilection, with nine out of the ten reported cases occurring in males, in contrast to elsewhere in the head and neck where myxomas predominate in females [6]. More than half of patients with laryngeal myxomas have a smoking history although it is uncertain however, whether smoking plays a role in the development of these neoplasms. Myxomas of the larynx tend to occur in older individuals between the 6th to 8th decades. Myxomas of the head and neck have been reported in adolescents and young adults. Pediatric patients most commonly present with myxomas of the mandible [6].

\section{Imaging Studies}

Radiographic imaging is seldom performed as the lesions usually resemble laryngeal polyps clinically. In Baruah's case, a non-contrast-enhanced computed tomography revealed a homogenous well-defined mass [4]. In a case presented by Sena, a computed tomographic scan revealed a tumor consistent with a fluid-filled laryngocele [3].

\section{Gross and Microscopic Characteristics}

Grossly, myxomas appear as gray to white gelatinous, encapsulated tumors. They may have a glistening surface. Myxomas are typically rubbery but may be firm depending on the cellular content [8].

Histologically, myxomas lack a capsule and tend to infiltrate the surrounding tissues. They contain bland looking stellate to spindled cells with long, thin cytoplasmic processes in a background of abundant basophilic mucoid material. The stroma is rich with mucopolysaccharides with a variable meshwork of reticulin and collagen [9]. Myxomas remarkably lack the presence of blood vessels [7]. Cellular atypia, pleomorphism or mitotic figures, necrosis and hemorrhage are usually absent. Few inflammatory cells, especially lymphocytes, may be noted.

\section{Differential Diagnosis}

\section{Clinical Differential Diagnosis}

Clinical differential diagnosis includes vocal nodule, vocal polyp or a cyst. Vocal cord nodules present as bilateral symmetrical swellings of the anterior to mid third of the vocal folds. These tend to occur in children and adolescents and predominate in adult females [10]. They differ from laryngeal myxomas in that the myxomas are generally present in adult males with a smoking history and are unilateral. Mucous retention and epidermoid cysts are more common in females. The vocal folds associated with 


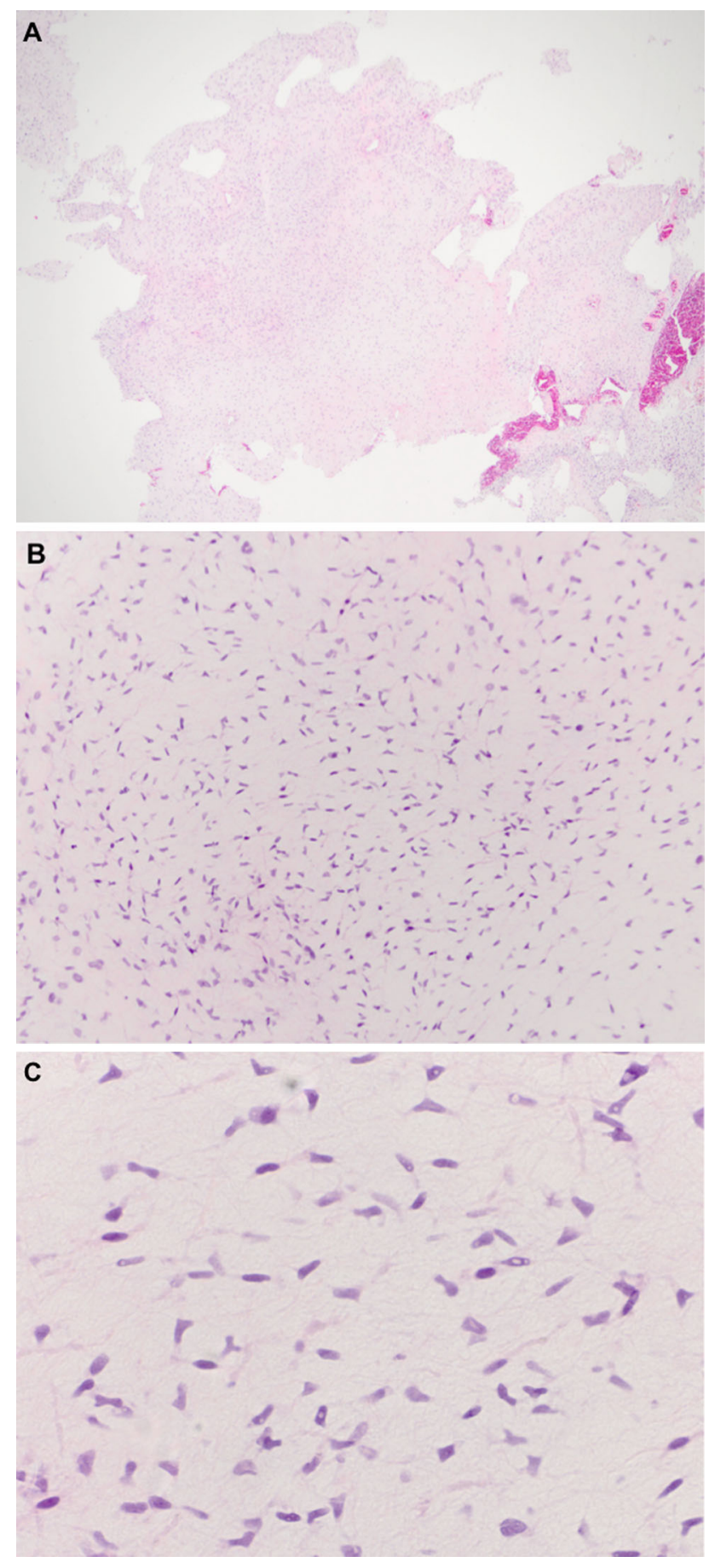

Fig. 2 Histological features of a laryngeal myxoma. a Low power view showing the polypoid nature of the myxoma. $\mathbf{b}$ Scant vascularity with abundant spindle cells in a background of myxoid material. c High power demonstrating the stellate cells with branching cytoplasmic processes and bland nuclear features

mucous retention cysts and with epidermoid cysts appear asymmetric with evidence of a submucosal mass [10]. The entity most difficult to distinguish from a laryngeal myxoma is a laryngeal polyp. Clinically, they are indistinguishable.

\section{Histologic Differential Diagnosis}

The histologic differential diagnosis includes myxoid liposarcoma, myxoid chondrosarcoma and laryngeal polyp [8]. Well differentiated myxoid liposarcomas and chondrosarcomas may appear histologically bland and may be difficult to distinguish from myxomas. Immunohistochemical studies may prove helpful as $\mathrm{S} 100$ protein is consistently negative for myxomas but positive in lipoblasts and chondroblasts, while more than half of myxomas show immunoreactivity for smooth muscle actin and CD34 [9]. In our case the lesional spindle cells stained positively for CD34 but were negative for smooth muscle actin and S100.

Vocal cord polyps have prominent stromal myxoid change but with prominence of blood vessels. Hemorrhage, hemosiderin-laden macrophages and hyalinized basement membrane are also frequently present in laryngeal polyps $[3,11]$. Laryngeal myxomas have scant vascularity, no fibrin and no hemorrhage.

\section{Syndromic Associations}

In a young patient with multiple myxomas, it is important to rule out Carney complex. Carney complex is an autosomal dominant condition in which the patients present with myxomas of the heart and skin, hyperpigmentation of the skin and endocrine overactivity [12]. Lentigines are located around the lips, on the eyelids, and ears and present as flat, poorly circumscribed brown to black small macules. Cutaneous myxomas are the third most common skin manifestation of Carney complex. They typically arise in the head and neck region, and are often found on the eyelids, ears, and in the external ear canal. They appear as sessile, small, dark pink papules and large papillary pedunculated lesions and may be clinically misdiagnosed as papillomas or fibromas. The patients may exhibit endocrine overactivity including Cushing syndrome and may develop tumors of pituitary, thyroid, testis or ovary. Although laryngeal myxomas have not been reported in Carney's complex, the ubiquitous distribution of myxomas in this complex suggests that this association cannot be completely excluded.

Laryngeal myxomas have also been reported to occur with mucopolysaccharidosis II (MPS II) or Hunter's syndrome [10, 13]. MPS II is a storage disorder due to a deficiency in iduronate sulphatase characterized by the intracellular and extracellular accumulation of glycosaminoglycan. This accumulation leads to obstruction of the airway causing chronic respiratory failure. Since there is only a single reported case of a concurrent MPS II and laryngeal myxoma, it is difficult to assign a causal relationship. 


\section{Treatment and Prognosis}

Treatment of a myxoma is determined by its size and location. Although they appear encapsulated, myxomas are locally infiltrative and destructive [14] and may therefore recur following enucleation. Myxomas of soft tissue are less likely to recur than myxomas of bone or odontogenic origin [4]. Recurrence is usually within 2-3 years [7]. Complete surgical excision is the treatment of choice.

Acknowledgments The authors thank Jill M. Kramer, DDS, PhD of SUNY at Buffalo and Claudine Alexis MBA, MS at Department of Pathology Hofstra North Shore-LIJ School of Medicine for critical reading of this manuscript.

\section{References}

1. Chen KT, Ballecer RA. Laryngeal myxoma. Am J Otolaryngol. 1986;7(1):58-9.

2. Stout AP. Myxoma, the tumor of primitive mesenchyme. Ann Surg. 1948;127(4):706-19.

3. Sena T, Brady MS, Huvos AG, Spiro RH. Laryngeal myxoma. Arch Otolaryngol Head Neck Surg. 1991;117(4):430-2.
4. Baruah P, Jha DN, Karak AK, Kumar R. Laryngeal myxoma. J Laryngol Otol. 2001;115(3):231-2.

5. Tsunoda K, Nosaka K, Housui M, Murano E, Ishikawa M, Imamura Y. A rare case of laryngeal myxoma. J Laryngol Otol. 1997;111(3):271-3.

6. Andrews T, Kountakis SE, Maillard AA. Myxomas of the head and neck. Am J Otolaryngol. 2000;21(3):184-9.

7. Batsakis JG. Myxomas of soft tissues and the facial skeleton. Ann Otol Rhinol Laryngol. 1987;96(5):618-9.

8. Nakamura A, Iguchi $\mathrm{H}$, Kusuki M, Yamane $\mathrm{H}$, Matsuda $\mathrm{M}$, Osako S. Laryngeal myxoma. Acta Otolaryngol. 2008;128(1): $110-2$.

9. Idrees MT, Hessler R, Terris D, Mixson C, Wang BY. Unusual polypoid laryngeal myxoma. Mt Sinai J Med. 2005;72(4):282-4.

10. Altman KW. Vocal fold masses. Otolaryngol Clin North Am. 2007;40(5):1091-108.

11. Hadley J, Gardiner Q, Dilkes M, Boyle M. Myxoma of the larynx: a case report and a review of the literature. J Laryngol Otol. 1994;108(9):811-2.

12. Espiard S, Bertherat J. Carney complex. Front Horm Res. 2013;41:50-62.

13. Orliaguet O, Pépin JL, Veale D, Kelkel E, Pinel N, Lévy P. Hunter's syndrome and associated sleep apnoea cured by CPAP and surgery. Eur Respir J. 1999;13(5):1195-7.

14. Kim KM, Kim SC, Jeong HJ, Kie JH. Myxoma: life-threatening benign nonepithelial tumor of the larynx. Yonsei Med J. 1997; 38(3):187-9. 